\title{
Regadenoson in Europe: first-year experience of regadenoson stress combined with submaximal exercise in patients undergoing myocardial perfusion scintigraphy
}

\author{
M. Brinkert • E. Reyes • S. Walker • K. Latus • \\ A. Maenhout $\cdot$ R. Mizumoto $\cdot$ C. Nkomo . \\ K. Standbridge $\cdot$ K. Wechalekar $\cdot$ S. R. Underwood
}

Received: 21 June 2013 / Accepted: 14 October 2013 / Published online: 22 November 2013

(C) The Author(s) 2013. This article is published with open access at Springerlink.com

\begin{abstract}
Purpose Regadenoson was approved for clinical use in Europe in 2011. Since then, it has become the default form of stress at our institution. We have assessed the side-effect profile and tolerability of regadenoson in patients undergoing clinically indicated myocardial perfusion scintigraphy between July 2011 and July 2012.

Methods Clinical, stress and imaging data were recorded prospectively. Symptoms during stress were recorded and defined as mild, moderate or severe. An adverse event was defined as any symptom that persisted for more than $30 \mathrm{~min}$ or that required investigation or treatment.

Results Of 1,764 consecutive patients, 1,581 (90\%) received regadenoson combined with submaximal exercise unless contraindicated. Symptoms were common (63\%) but transient and well-tolerated. The severity of symptoms was recorded in most patients as mild (84\%). Dyspnoea (36\%) and chest discomfort (12\%) were the commonest side effects. Adverse events were reported in eight patients $(0.5 \%)$, thought to be vasovagal in seven of these. All patients recovered fully without sequelae. There were no deaths, myocardial infarction or hospital admissions. Regadenoson stress was performed in 206 patients (12\%) with asthma or chronic obstructive pulmonary disease (COPD) without bronchospasm or any other major side effect.
\end{abstract}

M. Brinkert $\cdot$ E. Reyes $\cdot$ S. Walker $\cdot$ K. Latus $\cdot$ A. Maenhout R. Mizumoto $\cdot$ C. Nkomo $\cdot$ K. Standbridge $\cdot$ K. Wechalekar $\cdot$

S. R. Underwood $(\bowtie)$

Royal Brompton Hospital, Sydney St, London SW3 6NP, UK

e-mail: srunderwood@imperial.ac.uk

E. Reyes $\cdot$ S. R. Underwood

National Heart \& Lung Institute, Imperial College London, London, UK
Conclusion We studied the symptom profile of regadenoson in the largest European cohort to date. Regadenoson combined with submaximal exercise was well tolerated, notably also in patients with asthma or COPD. The majority of regadenoson-related adverse events were vasovagal episodes without sequelae.

Keywords Myocardial perfusion scintigraphy . Regadenoson $\cdot$ Side effects $\cdot$ Safety $\cdot$ Tolerability

\section{Introduction}

Although dynamic exercise is the preferred form of stress for myocardial perfusion scintigraphy (MPS), many patients are unable to exercise maximally and pharmacological stress is common [1]. At our institution, pharmacological stress is the default form of stress because most patients have already been considered for or have undergone an exercise ECG. An efficient and effective way of stressing coronary function in this setting is with the use of vasodilators. Adenosine and dipyridamole are both potent primary coronary vasodilators with a nonselective action, which explains the side effects commonly associated with these agents [2-9]. To avoid side effects and potential adverse events, a number of selective adenosine $\mathrm{A}_{2 \mathrm{~A}}$ receptor agonists have been developed [10-14]. Of these, regadenoson is the only one approved for clinical use by the Food and Drug Administration. Approval was granted by the European Medicines Agency in 2010 and by the Royal Brompton \& Harefield NHS Foundation Trust New Drugs and Clinical Guidelines Committee in May 2011. Since July 2011, we have used regadenoson as the default form of stress, and we now have the largest experience outside North America. The main objective of this study was to assess the side effect profile, safety and tolerability of regadenoson in 
patients undergoing clinically indicated MPS. A secondary objective of the study was to compare this experience with other forms of cardiac stress.

\section{Methods}

Patient selection

Regadenoson stress was implemented at our institution on 22 July 2011. As part of an audit of clinical practice, we studied all patients who underwent clinically indicated MPS over the following 12 months. Clinical and imaging data were collected prospectively and retrieved for retrospective analysis from a dedicated database. The selection of stress agent was a clinical decision based upon using regadenoson by default with patients receiving another form of stress if this was preferred over regadenoson or there was a contraindication to the use of this agent (Fig. 1). Hence, in patients with suspected myocardial bridging, coronary anomaly or microvascular dysfunction as the primary cause of symptoms, dynamic exercise was the preferred form of stress. Patients who were suitable for vasodilator stress but self-reported caffeine consumption within $12 \mathrm{~h}$ of the test were given high-dose adenosine $(210 \mu \mathrm{g} / \mathrm{kg} / \mathrm{min})$ to overcome the antagonism mediated by caffeine on the adenosine receptors [15]. Patients with a contraindication to vasodilator stress received dobutamine. After 3 months, regadenoson was given to patients with obstructive airways disease irrespective of disease severity.

\section{Symptoms and adverse events}

Symptoms during stress were recorded and defined as mild, moderate or severe by the health professional (a clinical nurse specialist or a nuclear cardiologist) conducting the stress test. A mild symptom did not distress the patient, a moderate symptom did distress the patient but was self-limiting without the need for intervention, and a severe symptom distressed the patient and required some form of intervention to alleviate it. An adverse event was defined as any symptom that persisted for more than $30 \mathrm{~min}$ or that required investigation or treatment, for instance reversal of the stress agent by aminophylline.

\section{Stress MPS}

Regadenoson was administered intravenously as a rapid injection of $400 \mu \mathrm{g}$ over at least $10 \mathrm{~s}$ followed by a 5-ml saline flush. The radiopharmaceutical was administered intravenously approximately $20 \mathrm{~s}$ after regadenoson injection. Unless there was left bundle branch block or paced rhythm, regadenoson was combined with bicycle exercise at $0 \mathrm{~W}$ (free wheel), or 5, 10, 15 or $25 \mathrm{~W}$ depending on exercise tolerance. Supplemental exercise was initiated $1 \mathrm{~min}$ before regadenoson injection and continued for $2-3$ min after injection of regadenoson. ECG rhythm was monitored throughout and heart rate and blood pressure recorded every $2 \mathrm{~min}$ or more often if necessary until completion of the test. Patients with airways disease had regadenoson without pretreatment with a bronchodilator. To antagonize the effect of caffeine in patients who self-reported caffeine ingestion within $12 \mathrm{~h}$ before the test, adenosine was infused at a high dose of $210 \mu \mathrm{g} / \mathrm{kg} / \mathrm{min}$ over $6 \mathrm{~min}$ with supplemental exercise. Dobutamine was given intravenously at incremental doses of $5-10 \mu \mathrm{g} / \mathrm{kg} / \mathrm{min}$ every $3-5 \mathrm{~min}$ starting at $5-10 \mu \mathrm{g} / \mathrm{kg} / \mathrm{min}$ up to a maximal dose of $40 \mu \mathrm{g} / \mathrm{kg} / \mathrm{min}$. Dynamic exercise was performed on a bicycle ergometer at increasing workloads of $25-50 \mathrm{~W}$ every $2-3$ min until $\geq 85 \%$ of maximum predicted heart rate was reached or angina and ischaemic ECG changes developed.

\section{Imaging analysis}

All images were interpreted according to routine clinical practice by an experienced nuclear cardiologist. For the purpose of
Fig. 1 Flow diagram showing patient selection for stress testing according to routine clinical practice

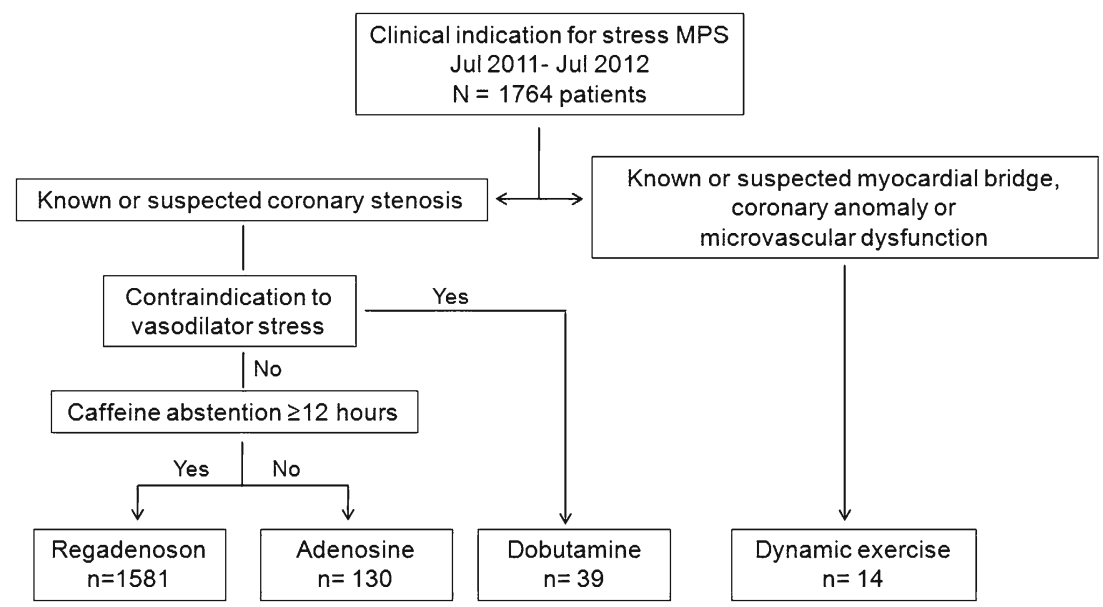


this study, further analysis was conducted in patients who experienced an adverse event following regadenoson injection. Quantitative perfusion SPECT software (QPS, version 2008; Cedars-Sinai Medical Center, Los Angeles, CA) was used to calculate the total burden of ischaemia as the total perfusion deficit (TPD) difference between stress and rest images. Total ischaemic burden was defined as mild, moderate or severe if TPD was $<6 \%, 6-9 \%$ or $\geq 10 \%$, respectively. In addition, the stress and rest summed segmental scores were calculated using a 17-segment model with each segment scored from 0 to 4 ( 0 normal, 1 mild, 2 moderate, 3 severe defect and 4 absent tracer uptake). The extent and severity of ischaemia was defined as the difference between summed stress and summed rest scores (SDS). A SDS $<6$ was considered mild, $7-12$ moderate and $>12$ severe [16]. Left ventricular ejection fraction was computed using Quantitative Gated SPECT software (QGS, version 2008; Cedars-Sinai Medical Center).

\section{Statistical analysis}

Data summary and statistical comparisons were performed using Microsoft Excel Analysis Toolpak and SPSS (IBM SPSS Statistics v20). Continuous variables were compared using analysis of variance; categorical variables were compared using the chi-squared test. Logistic regression analysis was performed to examine the association between stress-induced adverse events and potential predictors of such events.

\section{Results}

\section{Patient characteristics}

A total of 1,764 consecutive patients underwent stress MPS between 22 July 2011 and 28 July 2012. Of these, $69 \%$ were male; mean \pm SD age was $67 \pm 11$ years and mean \pm SD body mass index $28 \pm 5 \mathrm{~kg} / \mathrm{m}^{2}$. The majority of patients $(90 \%)$ underwent regadenoson stress while the remainder had adenosine $(7 \%)$, dobutamine $(2 \%)$ or dynamic exercise $(1 \%)$. The prevalence of cardiovascular risk factors and other characteristics of the population are listed in Table 1. There were no significant differences between groups except for lung disease, which was more common $(83 \%)$ in the dobutamine group. Symptoms on presentation are shown in Table 2. Of the 1,764 patients, $73 \%$ had a history of chest pain, and in $24 \%$ of these patients the chest pain was angina, $60 \%$ had dyspnoea and $9 \%$ had a history of heart failure, but less than $1 \%$ had severe heart failure. Dyspnoea was more frequent in the dobutamine group, and there was a small excess of patients with a history of heart failure in the adenosine and dobutamine groups.
Haemodynamic response to stress

There was a statistically significant but clinically unimportant difference in resting blood pressure between groups (Fig. 2). Heart rate increased by $28 \pm 17 \mathrm{bpm}$ with regadenoson stress, $19 \pm 18 \mathrm{bpm}$ with adenosine, $31 \pm 24 \mathrm{bpm}$ with dobutamine and $51 \pm 24 \mathrm{bpm}$ with dynamic exercise (Fig. 3). There was no significant change in blood pressure from rest to peak stress in the regadenoson and adenosine groups, while there was a significant reduction in the dobutamine group. The haemodynamic response to vasodilators was modified by concurrent dynamic exercise: median workload $25 \mathrm{~W}(0 \mathrm{~W}, 100 \mathrm{~W})$ for regadenoson vs. $15 \mathrm{~W}(0 \mathrm{~W}, 75 \mathrm{~W})$ for adenosine.

\section{Symptoms and side effects}

Symptoms were common with all forms of pharmacological stress with $63 \%$ of patients in the regadenoson group, $75 \%$ of patients in the adenosine group, $46 \%$ in the dobutamine group and $36 \%$ in the exercise group $(P=0.001$, Fig. $4 a)$ reporting at least one symptom. Dyspnoea (36\%) and chest discomfort (12\%) were the commonest side effects following regadenoson injection. Chest discomfort and flushing occurred more often with adenosine (29\% and $25 \%$, respectively) than with regadenoson (12\% and $7 \%$, respectively), but lightheadedness was more common with regadenoson (7 \% vs. $1 \%$ for adenosine; Table 3). Diarrhoea was reported by 12 patients $(1 \%)$ in the regadenoson group compared with none in the other groups, but this difference was not statistically significance $(P=0.9)$. Chest discomfort and dyspnoea were the commonest side effects in the dobutamine group while dyspnoea was the most frequent side effect in the exercise group. The severity of symptoms did not differ significantly between stress agents $(P=0.3)$ with most symptoms graded as mild: $84 \%, 88 \%$, $82 \%$ and $60 \%$ in the regadenoson, adenosine, dobutamine and exercise groups, respectively (Table 4, Fig. 4b).

\section{Adverse events}

There were no deaths, myocardial infarction or hospital admission following stress MPS. Adverse events were observed in eight patients $(0.5 \%)$, all in the regadenoson group (Table 5). Seven of the eight events were episodes of symptomatic hypotension with inappropriate bradycardia or failure of compensatory tachycardia, and they were therefore classified as vasovagal. One of these occurred after intravenous cannulation and before regadenoson injection, and the others occurred between 2 and 10 min after injection. Two episodes occurred in patients who did not exercise. Of all vasovagal events, three were moderate and two severe; the two severe episodes progressed to sinus arrest and asystole lasting $30 \mathrm{~s}$ and $10 \mathrm{~s}$ and requiring CPR. Aminophylline was administered to three patients. All patients recovered fully without sequelae. No association was 
Table 1 Patient demographics and clinical characteristics

\begin{tabular}{|c|c|c|c|c|c|c|c|c|c|c|c|}
\hline & \multicolumn{2}{|l|}{ Global } & \multicolumn{2}{|c|}{ Adenosine } & \multicolumn{2}{|c|}{ Regadenoson } & \multicolumn{2}{|c|}{ Dobutamine } & \multicolumn{2}{|c|}{ Exercise } & \multirow[t]{2}{*}{$P$} \\
\hline & $n$ & $\%$ & $n$ & $\%$ & $n$ & $\%$ & $n$ & $\%$ & $n$ & $\%$ & \\
\hline \multicolumn{12}{|l|}{ No. of patients } \\
\hline Total & 1,764 & 100 & 130 & 7 & 1,581 & 90 & 39 & 2 & 14 & 1 & $\mathrm{n} / \mathrm{a}$ \\
\hline Male & 1,211 & 69 & 96 & 74 & 1,079 & 68 & 26 & 67 & 10 & 71 & 0.6 \\
\hline Age (years), mean $\pm \mathrm{SD}$ & $67 \pm 11$ & - & $69 \pm 12$ & - & $67 \pm 11$ & - & $68 \pm 13$ & - & $56 \pm 25$ & - & $<0.001$ \\
\hline $\mathrm{BMI}\left(\mathrm{kg} / \mathrm{m}^{2}\right)$, mean $\pm \mathrm{SD}$ & $28 \pm 5$ & - & $27 \pm 5$ & - & $28 \pm 5$ & - & $30 \pm 8$ & - & $27 \pm 4$ & - & 0.01 \\
\hline Diabetes & 411 & 24 & 29 & 23 & 369 & 23 & 12 & 31 & 1 & 7 & 0.3 \\
\hline Hypertension & 1,300 & 74 & 96 & 74 & 1,167 & 74 & 27 & 69 & 10 & 71 & 0,9 \\
\hline Hyperlipidaemia & 1324 & 76 & 102 & 78 & 1,189 & 75 & 24 & 62 & 9 & 64 & 0.3 \\
\hline Smokers & 135 & 11 & 16 & 19 & 116 & 7 & 3 & 8 & 0 & 0 & 0.1 \\
\hline Known coronary artery disease & 1023 & 59 & 80 & 63 & 921 & 58 & 17 & 44 & 5 & 36 & 0.1 \\
\hline Myocardial infarction & 460 & 26 & 37 & 28 & 413 & 26 & 7 & 18 & 3 & 21 & 0.7 \\
\hline Percutaneous coronary intervention & 627 & 36 & 43 & 33 & 571 & 36 & 10 & 26 & 3 & 21 & 0.4 \\
\hline Coronary artery bypass grafting & 285 & 16 & 28 & 22 & 251 & 16 & 4 & 10 & 2 & 14 & 0.3 \\
\hline Lung disease & 304 & 18 & 25 & 20 & 246 & 16 & 30 & 83 & 3 & 25 & $<0.001$ \\
\hline
\end{tabular}

$P$ values are between stress groups (statistical significance at $P<0.05$ )

found between the incidence of adverse events during stress and clinical and imaging characteristics including known coronary artery disease (CAD), older age ( $>65$ years), cardiovascular risk factors and inducible ischaemia on MPS $(P>0.05$ for all). In the regadenoson group, there was a significant reduction in heart rate and systolic blood pressure during stress in patients who experienced at least one adverse event compared with those who remained free of complications (heart rate $-6 \pm 18 \mathrm{bpm}$ vs.

Table 2 Clinical history and presenting symptoms

\begin{tabular}{|c|c|c|c|c|c|c|c|c|c|c|c|}
\hline & \multicolumn{2}{|c|}{ Global } & \multicolumn{2}{|c|}{ Adenosine } & \multicolumn{2}{|c|}{ Regadenoson } & \multicolumn{2}{|c|}{ Dobutamine } & \multicolumn{2}{|c|}{ Exercise } & \multirow[t]{2}{*}{$P$} \\
\hline & $n$ & $\%$ & $n$ & $\%$ & $n$ & $\%$ & $n$ & $\%$ & $n$ & $\%$ & \\
\hline \multicolumn{12}{|l|}{ Chest discomfort } \\
\hline None & 475 & 27 & 29 & 22 & 431 & 27 & 9 & 23 & 5 & 36 & \multirow[t]{8}{*}{$>0.5$} \\
\hline Non-anginal & 8 & 0 & 0 & 0 & 8 & 1 & 0 & 0 & 0 & 0 & \\
\hline Atypical chest pain & 641 & 36 & 46 & 35 & 572 & 36 & 15 & 38 & 6 & 43 & \\
\hline Angina & 430 & 24 & 34 & 26 & 388 & 25 & 10 & 26 & 1 & 7 & \\
\hline CCS 1 & 274 & 66 & 22 & 69 & 244 & 65 & 7 & 64 & 1 & 100 & \\
\hline $\operatorname{CCS} 2$ & 99 & 24 & 4 & 13 & 91 & 24 & 4 & 36 & 0 & 0 & \\
\hline $\mathrm{CCS} 3$ & 42 & 10 & 6 & 19 & 39 & 10 & 0 & 0 & 0 & 0 & \\
\hline $\operatorname{CCS} 4$ & 0 & 0 & 0 & 0 & 0 & 0 & 0 & 0 & 0 & 0 & \\
\hline Nonspecified chest pain & 209 & 12 & 21 & 16 & 181 & 11 & 5 & 13 & 2 & 14 & \\
\hline Heart failure & 137 & 9 & 20 & 17 & 110 & 8 & 6 & 21 & 1 & 8 & \multirow[t]{5}{*}{0.002} \\
\hline NYHA 1 & 51 & 3 & 5 & 4 & 43 & 3 & 2 & 7 & 1 & 8 & \\
\hline NYHA 2 & 40 & 3 & 5 & 4 & 32 & 2 & 3 & 11 & 0 & 0 & \\
\hline NYHA 3 & 41 & 3 & 10 & 8 & 31 & 2 & 0 & 0 & 0 & 0 & \\
\hline NYHA 4 & 5 & 0 & 0 & 0 & 4 & 0 & 1 & 4 & 0 & 0 & \\
\hline Dyspnoea & 1,041 & 60 & 87 & 70 & 915 & 59 & 33 & 89 & 6 & 43 & \multirow[t]{4}{*}{0.001} \\
\hline Mild & 637 & 37 & 43 & 34 & 583 & 37 & 9 & 24 & 2 & 14 & \\
\hline Moderate & 332 & 19 & 35 & 28 & 273 & 18 & 21 & 57 & 3 & 21 & \\
\hline Severe & 72 & 4 & 9 & 7 & 59 & 4 & 3 & 8 & 1 & 7 & \\
\hline
\end{tabular}

CCS Canadian Cardiovascular Society angina class, NYHA New York Heart Association heart failure class

Statistical significance at $P<0.05$ 


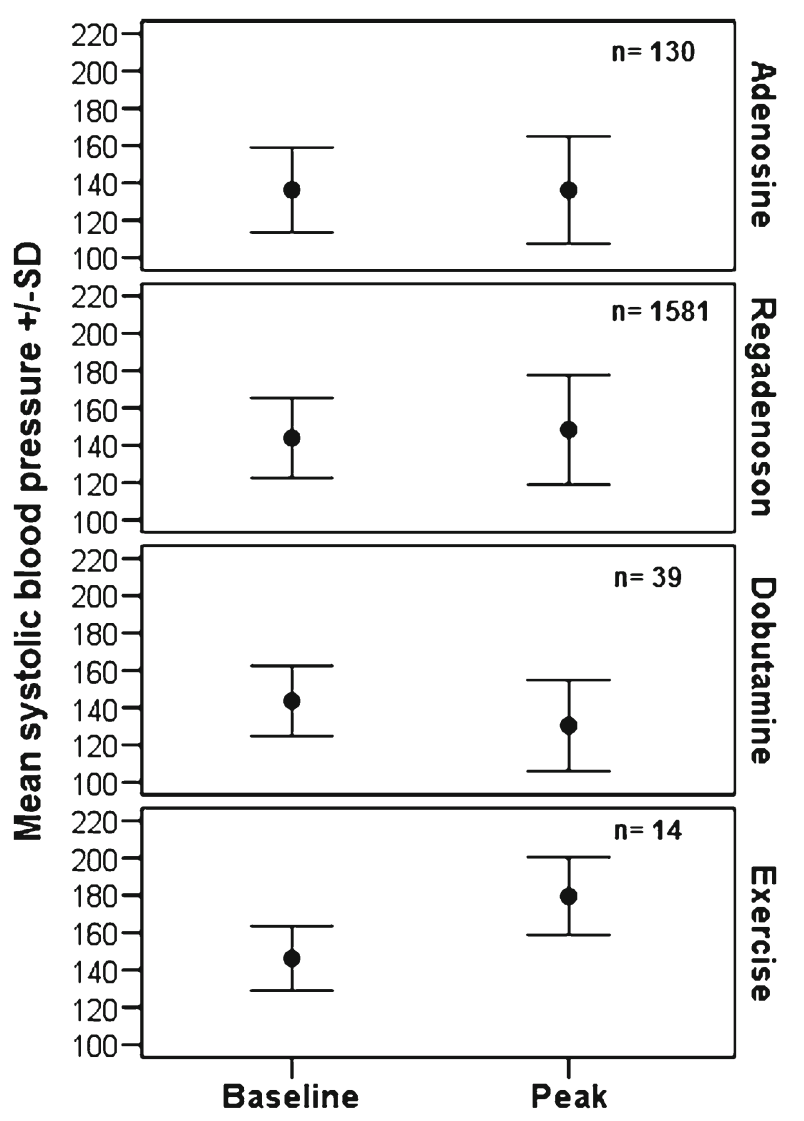

4 Fig. 2 Blood pressure response to stress. a Baseline and peak systolic blood pressure; b baseline and peak diastolic blood pressure. Baseline measures were obtained immediately before starting the stress test. Peak blood pressure was that with the largest change over the duration of the test. Values are means \pm 1 standard deviation

$28 \pm 16 \mathrm{bpm}, P=0.001$; and systolic blood pressure $-36 \pm$ $34 \mathrm{mmHg}$ vs. $5 \pm 26 \mathrm{mmHg}, P=0.01)$. Only heart rate and systolic blood pressure reduction during stress predicted the likelihood of an adverse event after regadenoson injection ( $P>0.01$ for both).

\section{Lung disease}

Lung disease including airways obstruction was documented by clinical history in 297 patients (17\%) of whom 145 (49\%) had asthma, $111(37 \%)$ chronic obstructive pulmonary disease (COPD), 34 (11\%) interstitial lung disease and 7 (2\%) bronchiectasis. Of these 297 patients, 242 (81\%) received regadenoson. Of all patients with a history of asthma in the regadenoson group, $71 \%$ had intermittent symptoms, $26 \%$ mild persistent symptoms, and $3 \%$ moderate symptoms, and none had severe persistent asthma. No patient developed bronchospasm with regadenoson, but one patient (male, 79 years old) with a history of previous myocardial infarction (MI) but not known to have airways disease developed mild bronchospasm. The bronchospasm developed soon after
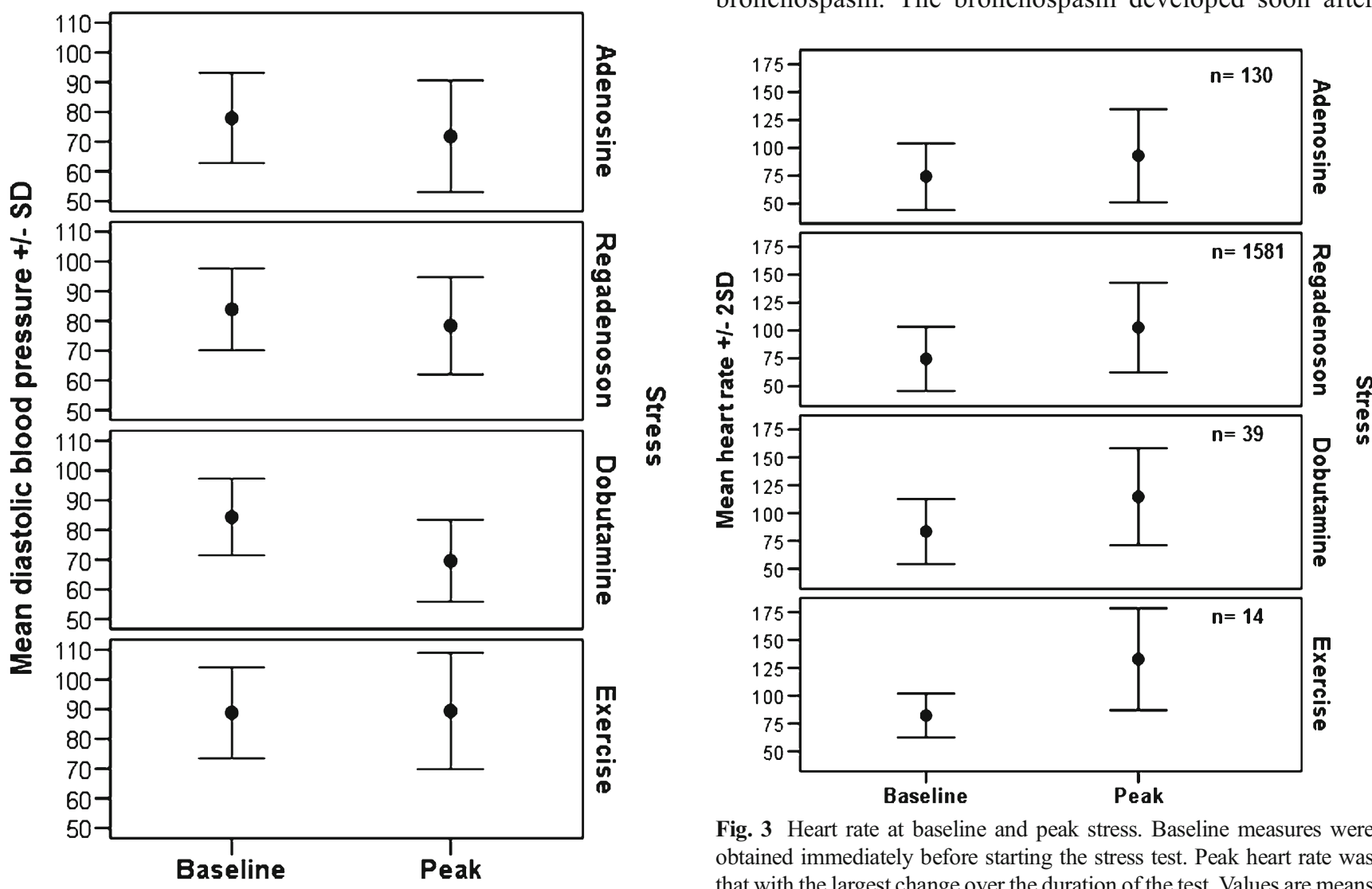

Fig. 3 Heart rate at baseline and peak stress. Baseline measures were obtained immediately before starting the stress test. Peak heart rate was that with the largest change over the duration of the test. Values are means \pm 2 standard deviation 
Fig. 4 Symptoms during stress: a frequency; b severity. ${ }^{*} P \leq 0.05$

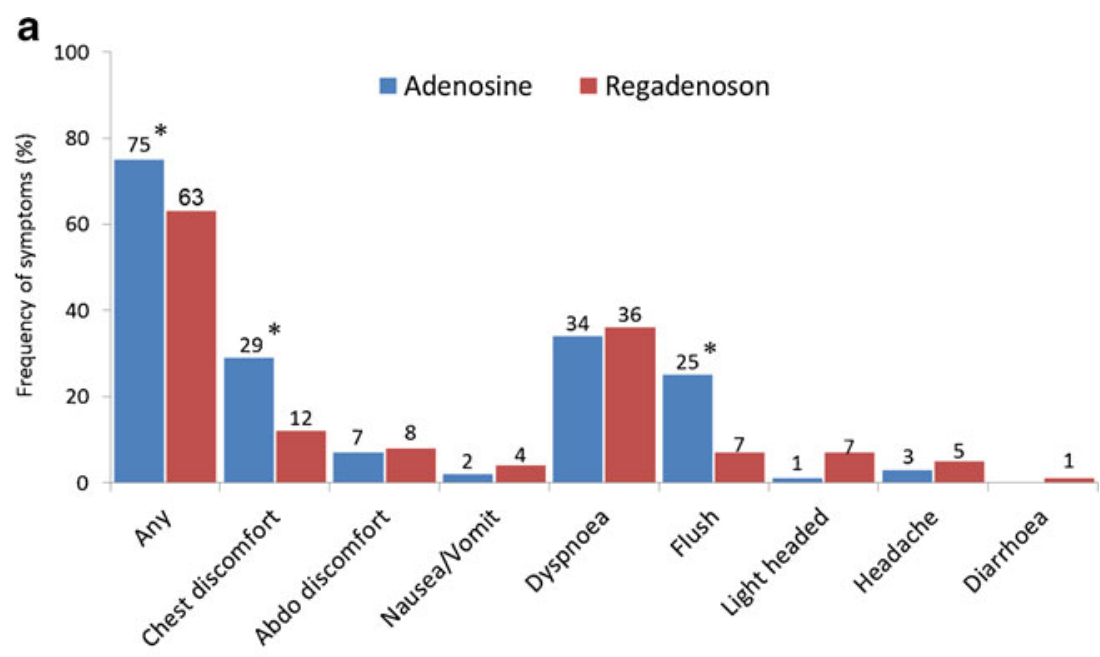

b

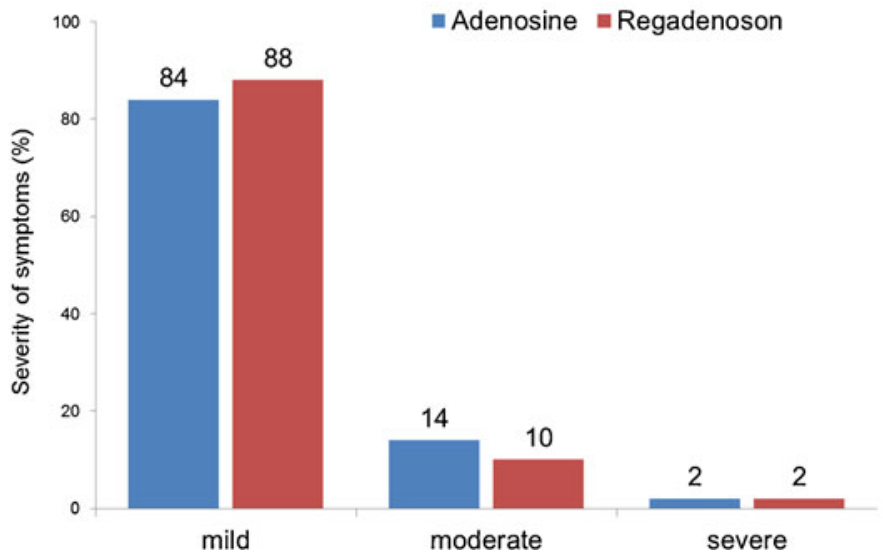

injection of regadenoson and resolved shortly after inhalation of salbutamol. Most patients in the dobutamine group (77\%) had some form of lung disease, mainly asthma or COPD. Of these, $13 \%$ had intermittent asthma, $19 \%$ mild persistent asthma, $44 \%$ moderate persistent asthma and $15 \%$ severe persistent asthma. None of the patients who underwent dobutamine stress experienced any respiratory complications.

\section{Imaging results}

A total of 673 MPS studies (38\%) were normal. Among abnormal scans, a reversible or inducible myocardial perfusion abnormality was present in 946 (54\%). A representative patient is shown in Fig. 5. Of these, 366 (21\%) studies showed an additional fixed abnormality consistent with myocardial damage (full- or partial-thickness infarction). No inducible ischaemia but evidence of infarction was observed in the remaining 141 patients $(8 \%)$. Four studies were considered non-diagnostic $(0.2 \%)$. Among patients who experienced at least one stress-related adverse event $(n=8)$, mild to moderate inducible ischaemia was present in 5 of 7 MPS studies; none of the studies showed severe ischaemia or severe left ventricular dysfunction on ECG-gated images (Table 5). In one patient with severe vasovagal response, imaging was delayed $>45$ min post-thallium injection and hence no stress images were obtained.

\section{Discussion}

This report summarizes our first year of experience performing regadenoson stress in patients with suspected or known CAD. To the best of our knowledge, this is the largest series of patients undergoing clinically indicated regadenoson MPS in Europe. These results confirm previous observations and show that regadenoson in this setting is well tolerated and safe with no deaths, hard cardiac events or hospital admission following its administration. The rate of other untoward events was $0.5 \%$ and these were mainly vasovagal episodes that resolved without sequelae, although two patients received CPR as part of medical management.

Our results are very similar to those of previous studies including the phase III ADVANCE clinical trials. In these studies, side effects were reported in slightly over $70 \%$ of 
Table 3 Symptoms and adverse events

\begin{tabular}{|c|c|c|c|c|c|c|c|c|c|c|}
\hline \multirow{2}{*}{$\begin{array}{l}\text { Table } 3 \\
\text { events }\end{array}$} & \multirow[t]{2}{*}{ Event } & \multicolumn{2}{|c|}{ Adenosine } & \multicolumn{2}{|c|}{ Regadenoson } & \multicolumn{2}{|c|}{ Dobutamine } & \multicolumn{2}{|c|}{ Dynamic } & \multirow[t]{2}{*}{$P$} \\
\hline & & $n$ & $\%$ & $n$ & $\%$ & $n$ & $\%$ & $n$ & $\%$ & \\
\hline & Any & 97 & 75 & 996 & 63 & 18 & 46 & 5 & 36 & 0.001 \\
\hline & Chest discomfort & 38 & 29 & 193 & 12 & 11 & 28 & 1 & 7 & $<0.001$ \\
\hline & Palpitations & 0 & 0 & 11 & 1 & 1 & 3 & 0 & 0 & 0.2 \\
\hline & Abdominal discomfort & 9 & 7 & 132 & 8 & 0 & 0 & 0 & 0 & 0.2 \\
\hline & Nausea/vomiting & 2 & 2 & 56 & 4 & 1 & 3 & 0 & 0 & 0.7 \\
\hline & Diarrhoea & 0 & 0 & 12 & 1 & 0 & 0 & 0 & 0 & 0.9 \\
\hline & Dyspnoea & 44 & 34 & 565 & 36 & 7 & 18 & 4 & 29 & 0.1 \\
\hline & Flushing & 32 & 25 & 114 & 7 & 0 & 0 & 0 & 0 & $<0.001$ \\
\hline & Light-headedness & 1 & 1 & 114 & 7 & 2 & 5 & 0 & 0 & 0.1 \\
\hline & Headache & 4 & 3 & 86 & 5 & 1 & 3 & 0 & 0 & 0.8 \\
\hline & Fatigue & 4 & 3 & 17 & 1 & 0 & 0 & 0 & 0 & 0.5 \\
\hline
\end{tabular}

Statistical significance at $P<0.05$

patients undergoing regadenoson stress [17, 18]. In the current study, just over $60 \%$ of patients experienced at least one side effect following regadenoson injection. The lower frequency of side effects in the current study might be explained by the addition of submaximal exercise, which is known to reduce the frequency and severity of vasodilator-related side effects [19]. As in previous studies [17, 18], most side effects were mild and well tolerated. We have also previously shown that side effects are less common with increasing BMI, although this aspect was not assessed in the study [20].

As shown by previous comparisons between regadenoson and adenosine stress, the frequency and intensity of side effects after regadenoson injection is similar to that of adenosine, but the nature and quality of side effects differs between the two agents; for example, chest discomfort and flushing are more common with adenosine than regadenoson, while headache and gastrointestinal symptoms are more frequent with regadenoson [17, 18]. Differences in the degree of vasodilation and sympathetic stimulation as well as differences in affinity for the adenosine receptors may account for this finding [21].

Gastrointestinal symptoms and especially diarrhoea have the potential for causing procedural delays that may compromise image quality and accuracy, particularly when ${ }^{201} \mathrm{Tl}$ is used. Nearly $1 \%$ of our patients had diarrhoea following regadenoson injection; however, all episodes were selflimiting and images were obtained in all patients. The frequency of diarrhoea in our series was significantly lower than the $11 \%$ found in a recent study [22]. It is possible that lack of awareness of causality between regadenoson and gastrointestinal symptoms and cultural differences might have prevented our patients from reporting this unpleasant side effect. However, it is also likely that the addition of dynamic exercise might have contributed to the lower frequency of gastrointestinal symptoms. Indeed, Thomas et al. have already shown that regadenoson combined with exercise is associated with a low frequency of gastrointestinal symptoms (5\%) [23].
Regadenoson was safe with no fatal or nonfatal cardiac events observed in the hours following its administration (up to $4 \mathrm{~h}$ after the procedure). There was no need for hospital admission following regadenoson stress and this is consistent with previous observations $[17,18]$. No association was found between the incidence of adverse events and several clinical and imaging parameters. In contrast to previous reports, most untoward adverse events were episodes of symptomatic hypotension associated with absolute or relative bradycardia following regadenoson injection [17]. To the best of our knowledge no vasovagal episodes have been described before [18].

It is beyond the scope of this report to explain the mechanism of action by which regadenoson might cause vasovagal syncope but we can hypothesize. In general, some individuals are prone to experiencing vasovagal episodes secondary to any investigation [24-26]. In one patient, vasovagal symptoms and signs developed soon after cannulation and before regadenoson was given. All other episodes occurred after regadenoson injection. A direct bradycardic effect of regadenoson seems unlikely. Regadenoson has little if any effect on the sinoatrial and atrioventricular nodes as demonstrated in previous animal models [27]. As expected, the incidence of bradyarrhythmias including advanced degrees of atrioventricular block after regadenoson administration is low [22]. Experimental studies have demonstrated that

Table 4 Severity of symptoms

\begin{tabular}{|c|c|c|c|c|c|c|c|c|c|}
\hline \multirow[t]{2}{*}{ Severity } & \multicolumn{2}{|c|}{ Adenosine } & \multicolumn{2}{|c|}{ Regadenoson } & \multicolumn{2}{|c|}{ Dobutamine } & \multicolumn{2}{|c|}{ Dynamic } & \multirow[t]{2}{*}{$P$} \\
\hline & $n$ & $\%$ & $n$ & $\%$ & $n$ & $\%$ & $n$ & $\%$ & \\
\hline Mild & 90 & 84 & 939 & 88 & 14 & 82 & 3 & 60 & 0.3 \\
\hline Moderate & 15 & 14 & 108 & 10 & 3 & 18 & 2 & 40 & \\
\hline Severe & 2 & 2 & 18 & 2 & 0 & 0 & 0 & 0 & \\
\hline
\end{tabular}

Statistical significance at $P<0.05$ 


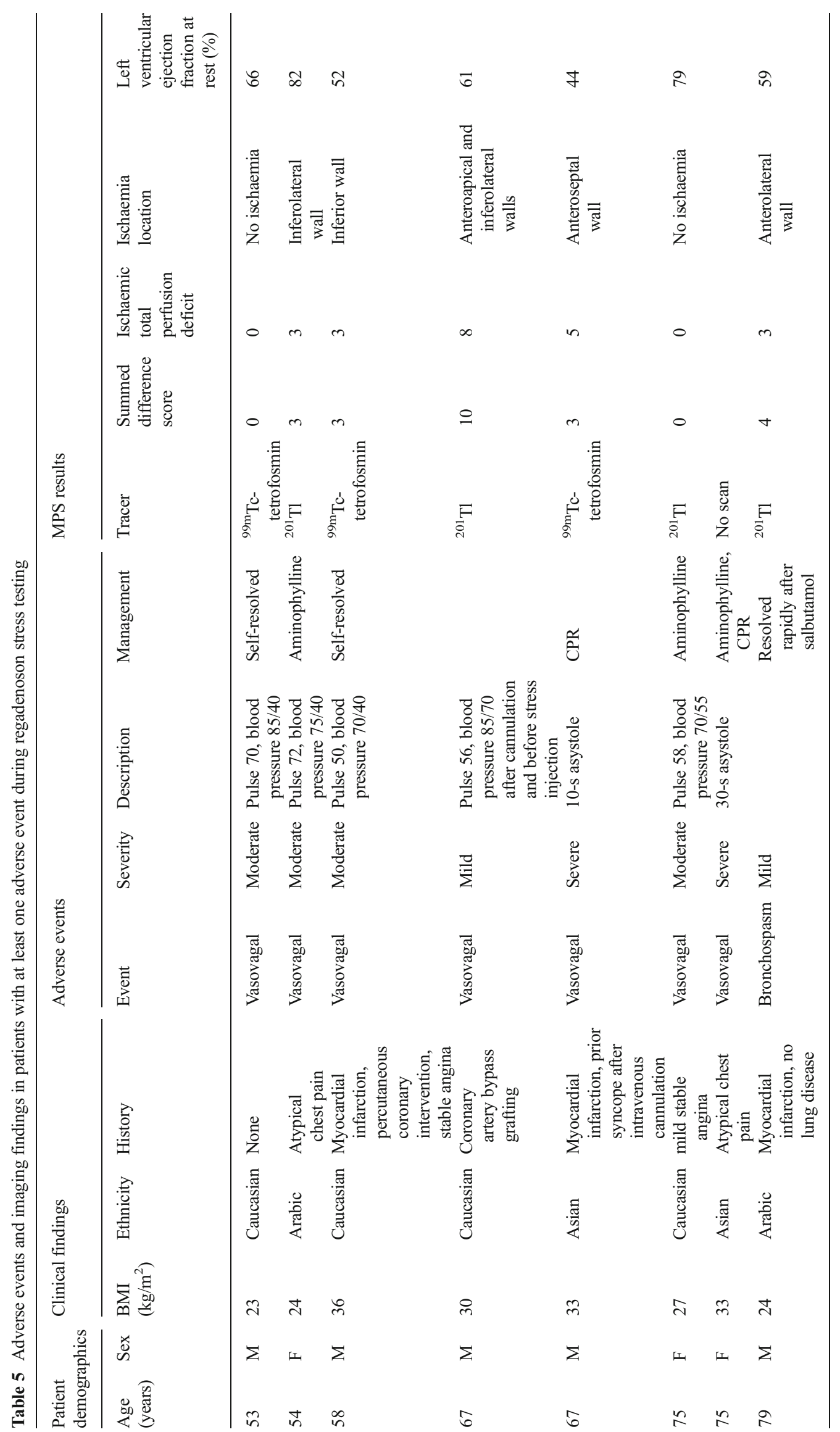




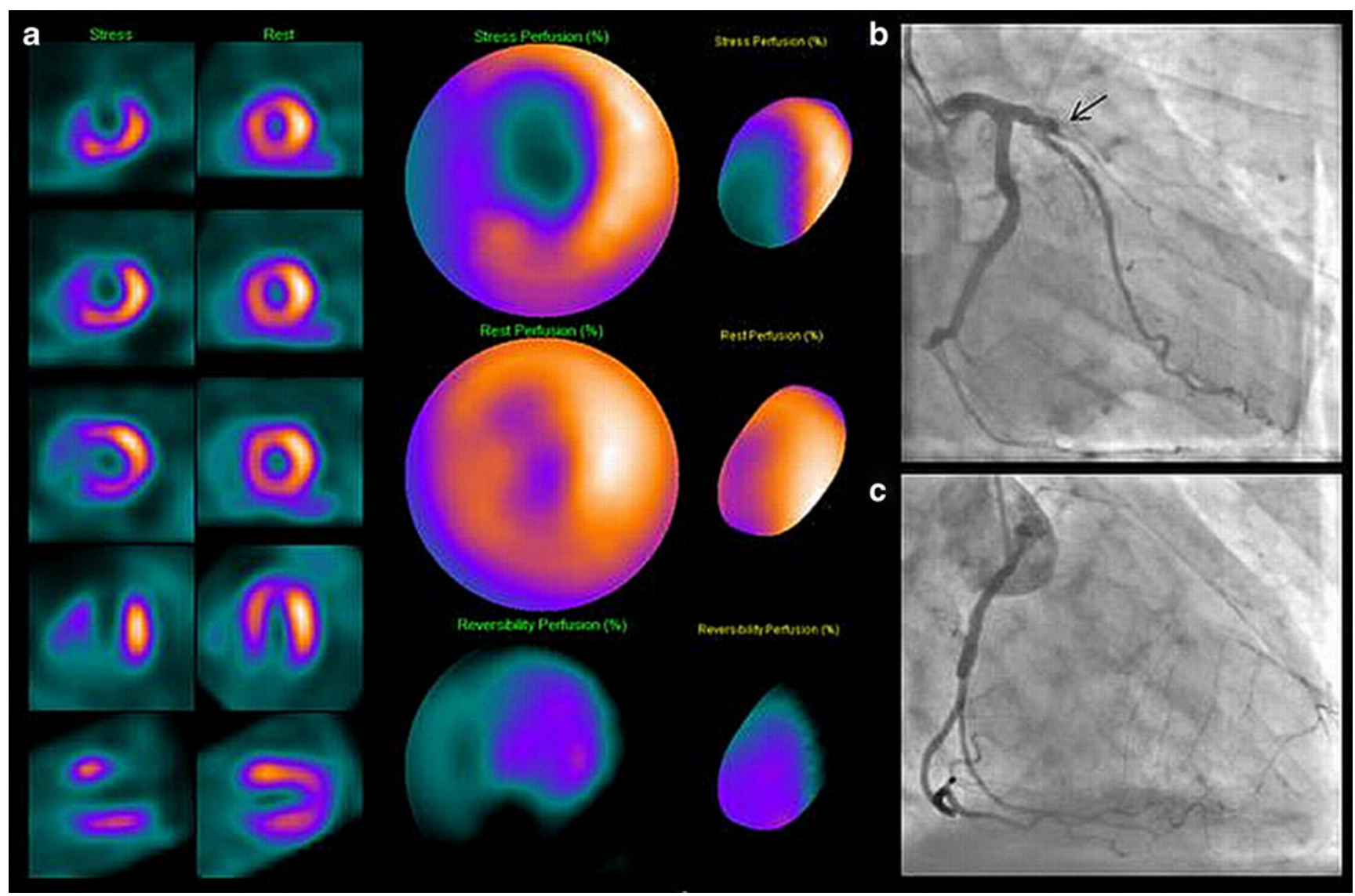

Fig. 5 A 71-year-old man with chest pain of suspected cardiac origin. a Regadenoson/rest ${ }^{201} \mathrm{Tl}$ MPS. The left ventricular tomograms and the corresponding polar maps show an extensive inducible perfusion abnormality in the left anterior descending coronary artery (LAD) territory. b, c X-ray coronary angiography demonstrates (b) total LAD occlusion (arrow) and (c) collateralization from the right coronary artery regadenoson has no significant $\mathrm{A}_{2 \mathrm{~B}}$ activity, and hence it should not cause peripheral vasodilation, although there may be some vasodilation mediated by peripheral $\mathrm{A}_{2 \mathrm{~A}}$ receptors. This, however, would result in sympathetic activation with tachycardia through the baroreceptor reflex. Two of the patients with a vasovagal episode had abdominal discomfort, nausea or vomiting before hypotension and bradycardia. Susceptible patients may have indirect vagal stimulation in response to these symptoms after regadenoson injection [28, 29]. This effect could have been exacerbated by the nonfasted status of our patients. Centrally mediated bradycardia and hypotension may also explain the observed adverse events. Indeed, animal studies have shown that activation of the $\mathrm{A}_{2}$ receptors in the posterior hypothalamus leads to bradycardia and hypotension [30]. A direct activation of $\mathrm{A}_{2}$ receptors in the human brain has not been proved. It is possible that in susceptible individuals, a rapid increase in sympathetic tone mediated by direct activation of $\mathrm{A}_{2 \mathrm{~A}}$ receptors in the sympathetic afferent nerves may result in reflex vagal discharge. This has already been proposed as a potential mechanism of action in adenosine-sensitive syncope [31].

\section{Lung disease}

Although lung disease is not a contraindication to the use of regadenoson, we were initially cautious and used dobutamine in patients with persistent asthma or moderate to severe COPD. None of the patients with airways disease who underwent regadenoson stress developed wheeze, and hence clinically significant bronchoconstriction following regadenoson seems unlikely. Therefore, regadenoson is a safe option in patients with lung disease and this has been confirmed in a recent study [32].

The proportions of abnormal (62\%) and ischaemic (54\%) scans among our patients were significantly higher than those reported in a recent study by Rozanski et al. looking at temporal trends in the frequency of abnormal and ischaemic MPS over the last two decades in patients referred to Cedars-Sinai Medical Center [33]. According to the study, there has been a progressive decline in the prevalence of abnormal MPS studies from approximately $41 \%$ in 1991 to only $9 \%$ in 2009. Likewise, there has been a reduction in the prevalence of ischaemic scans from $30 \%$ in 1999 to only $5 \%$ in 2009. It is important to bear in mind that for the purposes of the study, $24 \%$ of patients were excluded because of previous MI, mechanical revascularization, history of 
cardiomyopathy or valve disease. In contrast, our study included all patients referred for MPS regardless of medical history. Patients with known CAD, including those with previous MI or revascularization, comprised over half of our population. Our patients were on average 10 years older, with more cardiovascular risk factors and a higher frequency of anginal symptoms than in the Cedars-Sinai study, and this may partly explain the higher number of abnormal and ischaemic scans. These differences might also explain discrepancies found between this and recent studies on the side effect and safety profile of regadenoson, especially regarding the frequency of hypotensive episodes. In relative terms, our patient population was at "higher risk" of any complications during stress and hence likely to have exhibited a less favourable safety profile. Nonetheless, our findings indicate that regadenoson, as well as other forms of stress, are safe in this patient population with side effects and tolerability comparable to those observed in "lower risk" patients.

\section{Limitations}

This study was observational and did not control for sample size. Although statistical analysis was limited by the large difference between group sizes, descriptive comparison was possible. As mentioned above, it was not possible to explain the mechanism of action by which regadenoson might cause vasovagal episodes. This observation is hypothesis-generating and therefore further research is needed to elucidate the underlying mechanism(s).

\section{Conclusion}

In the largest European cohort to date, regadenoson combined with submaximal exercise has proved to be safe and well tolerated, notably also in patients with asthma and COPD. Most adverse events following regadenoson injection were vasovagal episodes. There is no clear direct mechanism by which regadenoson might cause vasovagal syncope.

Acknowledgments This work was supported in part by the Biomedical Research Unit of Royal Brompton \& Harefield NHS Foundation Trust.

\section{Conflicts of interests None.}

Open Access This article is distributed under the terms of the Creative Commons Attribution License which permits any use, distribution, and reproduction in any medium, provided the original author(s) and the source are credited.

\section{References}

1. Kelion AD, Anagnostopoulos C, Harbinson M, Underwood SR, Metcalfe M; British Nuclear Cardiology Society. Myocardial perfusion scintigraphy in the UK: insights from the British Nuclear Cardiology Society Survey 2000. Heart. 2005;91(4):iv2-5. doi:10. 1136/hrt.2004.049759.
2. Wilson RF, Wyche K, Christensen BV, Zimmer S, Laxson DD. Effects of adenosine on human coronary arterial circulation. Circulation. 1990;82:1595-606.

3. Rossen JD, Quillen JE, Lopez AG, Stenberg RG, Talman CL, Winniford MD. Comparison of coronary vasodilation with intravenous dipyridamole and adenosine. J Am Coll Cardiol. 1991;18:485-91.

4. Verani MS, Mahmarian JJ, Hixson JB, Boyce TM, Staudacher RA. Diagnosis of coronary artery disease by controlled coronary vasodilation with adenosine and thallium-201 scintigraphy in patients unable to exercise. Circulation. 1990;82:80-7.

5. Nguyen T, Heo J, Ogilby JD, Iskandrian AS. Single photon emission computed tomography with thallium-201 during adenosine-induced coronary hyperemia: correlation with coronary arteriography, exercise thallium imaging and two-dimensional echocardiography. J Am Coll Cardiol. 1990;16:1375-83.

6. Gupta NC, Esterbrooks DJ, Hilleman DE, Mohiuddin SM. Comparison of adenosine and exercise thallium-201 single-photon emission computed tomography (SPECT) myocardial perfusion imaging. The GE SPECT Multicenter Adenosine Study Group. J Am Coll Cardiol. 1992;19:248-57.

7. Ogilby JD, Iskandrian AS, Untereker WJ, Heo J, Nguyen TN, Mercuro J. Effect of intravenous adenosine infusion on myocardial perfusion and function. Hemodynamic/angiographic and scintigraphic study. Circulation. 1992;86:887-95.

8. Cerqueira MD, Verani MS, Schwaiger M, Heo J, Iskandrian AS. Safety profile of adenosine stress perfusion imaging: results from the Adenoscan Multicenter Trial Registry. J Am Coll Cardiol. 1994;23:384-9.

9. Ranhosky A, Kempthorne-Rawson J. The safety of intravenous dipyridamole thallium myocardial perfusion imaging. Intravenous Dipyridamole Thallium Imaging Study Group. Circulation. 1990;81:1205-9.

10. Hendel RC, Bateman TM, Cerqueira MD, Iskandrian AE, Leppo JA, Blackburn B, et al. Initial clinical experience with regadenoson, a novel selective A2A agonist for pharmacologic stress single-photon emission computed tomography myocardial perfusion imaging. J Am Coll Cardiol. 2005;46:2069-75. doi:10.1016/j.jacc.2005.05.097.

11. Udelson JE, Heller GV, Wackers FJ, Chai A, Hinchman D, Coleman PS, et al. Randomized, controlled dose-ranging study of the selective adenosine A2A receptor agonist binodenoson for pharmacological stress as an adjunct to myocardial perfusion imaging. Circulation. 2004;109:457-64. doi:10.1161/01.CIR.0000114523.03312.7D.

12. Glover DK, Ruiz M, Yang JY, Koplan BA, Allen TR, Smith WH, et al. Pharmacological stress thallium scintigraphy with 2cyclohexylmethylidenehydrazinoadenosine (WRC-0470). A novel, short-acting adenosine A2A receptor agonist. Circulation. 1996;94: 1726-32.

13. Zhao G, Linke A, Xu X, Ochoa M, Belloni F, Belardinelli L, et al. Comparative profile of vasodilation by CVT-3146, a novel A2A receptor agonist, and adenosine in conscious dogs. J Pharmacol Exp Ther. 2003;307:182-9. doi:10.1124/jpet.103.053306.

14. Trochu JN, Zhao G, Post H, Xu X, Belardinelli L, Belloni FL, et al. Selective A2A adenosine receptor agonist as a coronary vasodilator in conscious dogs: potential for use in myocardial perfusion imaging. J Cardiovasc Pharmacol. 2003;41:132-9.

15. Reyes E, Loong CY, Harbinson M, Donovan J, Anagnostopoulos C, Underwood SR. High-dose adenosine overcomes the attenuation of myocardial perfusion reserve caused by caffeine. J Am Coll Cardiol. 2008;52:2008-16. doi:10.1016/j.jacc.2008.08.052.

16. Hachamovitch R, Berman DS, Shaw LJ, Kiat H, Cohen I, Cabico JA, et al. Incremental prognostic value of myocardial perfusion single photon emission computed tomography for the prediction of cardiac death: differential stratification for risk of cardiac death and myocardial infarction. Circulation. 1998;97:535-43.

17. Iskandrian AE, Bateman TM, Belardinelli L, Blackburn B, Cerqueira $\mathrm{MD}$, Hendel RC, et al. Adenosine versus regadenoson comparative evaluation in myocardial perfusion imaging: results of the 
ADVANCE phase 3 multicenter international trial. J Nucl Cardiol. 2007;14:645-58. doi:10.1016/j.nuclcard.2007.06.114.

18. Cerqueira MD, Nguyen P, Staehr P, Underwood SR, Iskandrian AE, Investigators A-MT. Effects of age, gender, obesity, and diabetes on the efficacy and safety of the selective A2A agonist regadenoson versus adenosine in myocardial perfusion imaging integrated ADVANCE-MPI trial results. JACC Cardiovasc Imaging. 2008;1: 307-16. doi:10.1016/j.jcmg.2008.02.003.

19. Pennell DJ, Mavrogeni SI, Forbat SM, Karwatowski SP, Underwood SR. Adenosine combined with dynamic exercise for myocardial perfusion imaging. J Am Coll Cardiol. 1995;25:1300-9. doi:10. 1016/0735-1097(95)00011-R.

20. Reyes E, Staehr P, Olmsted A, Zeng D, Blackburn B, Cerqueira MD, et al. Effect of body mass index on the efficacy, side effect profile, and plasma concentration of fixed-dose regadenoson for myocardial perfusion imaging. J Nucl Cardiol. 2011;18:620-7. doi:10.1007/s12350011-9377-9.

21. Dhalla AK, Wong MY, Wang WQ, Biaggioni I, Belardinelli L. Tachycardia caused by A2A adenosine receptor agonists is mediated by direct sympathoexcitation in awake rats. J Pharmacol Exp Ther. 2006;316:695-702. doi:10.1124/jpet.105.095323.

22. Doukky R, Morales Demori R, Jain S, Kiriakos R, Mwansa V, Calvin JE. Attenuation of the side effect profile of regadenoson: a randomized double-blinded placebo-controlled study with aminophylline in patients undergoing myocardial perfusion imaging. "The ASSUAGE trial". J Nucl Cardiol. 2012;19:448-57.

23. Thomas GS, Thompson RC, Miyamoto MI, Ip TK, Rice DL, Milikien D, et al. The RegEx trial: a randomized, double-blind, placebo- and active-controlled pilot study combining regadenoson, a selective $\mathrm{A}(2 \mathrm{~A})$ adenosine agonist, with low-level exercise, in patients undergoing myocardial perfusion imaging. J Nucl Cardiol. 2009;16:63-72. doi:10.1007/s12350-008-9001-9.

24. Savage DD, Corwin L, McGee DL, Kannel WB, Wolf PA. Epidemiologic features of isolated syncope: the Framingham Study. Stroke J Cereb Circ. 1985;16:626-9.
25. Lipsitz LA, Wei JY, Rowe JW. Syncope in an elderly, institutionalised population: prevalence, incidence, and associated risk. Q J Med. 1985;55:45-54.

26. Mathias CJ, Deguchi K, Schatz I. Observations on recurrent syncope and presyncope in 641 patients. Lancet. 2001;357:348-53. doi:10. 1016/S0140-6736(00)03642-4.

27. Gao Z, Li Z, Baker SP, Lasley RD, Meyer S, Elzein E, et al. Novel short-acting A2A adenosine receptor agonists for coronary vasodilation: inverse relationship between affinity and duration of action of A2A agonists. J Pharmacol Exp Ther. 2001;298:209-18.

28. Palmer ED. The abnormal upper gastrointestinal vagovagal reflexes that affect the heart. Am J Gastroenterol. 1976;66:513-22.

29. Bortolotti M, Cirignotta F, Labo G. Atrioventricular block induced by swallowing in a patient with diffuse esophageal spasm. JAMA. 1982;248:2297-9.

30. Kang MJ, Park MS, Shin IC, Koh HC. Modification of cardiovascular response of posterior hypothalamic adenosine $\mathrm{A}(2)$ receptor stimulation by adenylate cyclase, guanylate cyclase and by K(ATP) channel blockade in anesthetized rats. Neurosci Lett. 2003;344:5761.

31. Saadjian AY, Levy S, Franceschi F, Zouher I, Paganelli F, Guieu RP. Role of endogenous adenosine as a modulator of syncope induced during tilt testing. Circulation. 2002;106: 569-74.

32. Prenner BM, Bukofzer S, Behm S, Feaheny K, McNutt BE. A randomized, double-blind, placebo-controlled study assessing the safety and tolerability of regadenoson in subjects with asthma or chronic obstructive pulmonary disease. J Nucl Cardiol. 2012;19: 681-92. doi:10.1007/s12350-012-9547-4.

33. Rozanski A, Gransar H, Hayes SW, Min J, Friedman JD, Thomson LE, et al. Temporal trends in the frequency of inducible myocardial ischemia during cardiac stress testing: 1991 to 2009. J Am Coll Cardiol. 2013;61:1054-65. doi:10.1016/j.jacc. 2012.11.056. 